\title{
Avaliação de materiais e revestimentos para o controle de incrustações do mexilhão dourado Limnoperna fortunei (Dunker, 1857)
}

\author{
Carlos Perez Bergmann ${ }^{1}$ \\ Maria Cristina Dreher Mansur ${ }^{2}$ \\ Daniel Pereira ${ }^{2 *}$ \\ Paulo Eduardo Aydos Bergonci ${ }^{2}$ \\ Cíntia Pinheiro dos Santos ${ }^{2}$ \\ Tania Basegio ${ }^{1}$ \\ Juliane Vicenzi ${ }^{1}$ \\ Silvio C. A. Santos ${ }^{3}$ \\ ${ }^{1} \mathrm{PPG}$ em Engenharia de Minas, Metalúrgica e de Materiais, \\ Universidade Federal do Rio Grande do Sul (UFRGS) \\ ${ }^{2}$ Centro de Ecologia (CENECO), UFRGS, Avenida Bento Gonçalves, 9500 \\ Setor 4, Prédio 43422, Sala 102, CEP 91540-000, Porto Alegre - RS, Brasil \\ ${ }^{3}$ AES Tietê, Departamento de Meio Ambiente, Promissão - SP, Brasil \\ *Autor para correspondência \\ dani.mdourado@gmail.com
}

Submetido em 20/08/2009

Aceito para publicação em 15/03/2010

\section{Resumo}

Foram realizados experimentos objetivando selecionar materiais e revestimentos com propriedades antiincrustantes para o controle do bivalve Limnoperna fortunei no sul do Brasil, em duas localidades: no canal principal do rio Jacuí, Porto Alegre, RS, e no reservatório da UHE Ibitinga, médio rio Tietê, SP. Os materiais testados foram: aço galvanizado, aço carbono, aço cobreado e cerâmica. Os revestimentos utilizados foram tintas: básica sem óxidos; básica com óxidos em concentração de 5\% como: $\mathrm{ZnO}$ nanométrico, partículas de $\mathrm{ZnO}$ convencional, $\mathrm{Cu} 2 \mathrm{O}$ nanométrico, partículas de $\mathrm{Cu} 2 \mathrm{O}$ convencional; e as tintas comerciais $\mathrm{R}$ e antibactérias. Corpos de prova com e sem revestimento (seis réplicas de cada), foram submersos na coluna d'água dos dois locais selecionados para os experimentos, entre outubro de 2006 e fevereiro de 2007. Quanto aos materiais metálicos, o cobre metálico, o aço galvanizado e aço carbono revestido com tinta comercial R e tinta antibactérias se demonstraram promissores no controle de incrustações do mexilhão dourado. Quanto ao material cerâmico, o revestimento de tinta base com $\mathrm{ZnO}$ comercial apresentou os melhores resultados. Nos materiais com e sem revestimentos, com elevadas densidades do bivalve, foi verificado que existe uma relação com a alta incidência de biofilmes, corrosão do material metálico e deterioração do revestimento.

Unitermos: água doce, bioincrustação, biofilmes, bivalve invasor, tintas antiincrustantes 


\section{Abstract}

Evaluation of materials and coatings to control incrustation by Limnoperna fortunei. Experiments aimed at selection of materials and coatings with antifouling properties for Limnoperna fortunei were conducted in southern Brazil, in two localities: next to the main stream of the Jacuí River, municipality of Porto Alegre, RS, and the reservoir of the UHE Ibitinga power plant, on the middle Tietê River, SP. The tested materials were galvanized steel, carbon steel, coppered steel, and ceramic. The coatings used consisted of several paintings without oxides or with oxides in 5\% concentrations such as nanometric $\mathrm{ZnO}$, conventional $\mathrm{ZnO}$ particles, nanometric $\mathrm{Cu}_{2} \mathrm{O}$, conventional $\mathrm{Cu}_{2} \mathrm{O}$ particles, and the paints commercial $\mathrm{R}$ and commercial bacteriostatic. The samples (six replicas each) were submerged in the water column at both places selected for the experiments, from October 2006 to February 2007. The metallic materials, steel coated with copper, galvanized steel, and carbon steel coated with $\mathrm{R}$ paint and with bacteriostatic paint, were considered promising in the control of Limnoperna fortunei encrustation. For the ceramic material, the coating with $\mathrm{ZnO}$ conventional paint was the one that presented the best results. On materials with and without coatings showing higher densities of encrusted golden mussels, a high incidence of biofilms, corrosion of the metallic material and coating deterioration were observed and considered to be related.

Keywords: antifouling coating, biofilms, bivalve invader, freshwater, macrofouling

\section{Introdução}

Os danos causados pelas incrustações do bivalve invasor Limnoperna fortunei (Dunker, 1857), popularmente conhecido com mexilhão dourado, vêm se tornando um problema de difícil solução para as empresas que dependem da captação de água dos mananciais hídricos para abastecer seus processos produtivos ou para gerar energia.

Diversas pesquisas têm sido realizadas no intuito de investigar materiais e revestimentos, com base na engenharia de superfícies, com potencial de utilização no controle das incrustações do mexilhão dourado em plantas industriais, principalmente em unidades geradoras de energia. Faria et al. (2006), com base em experimento realizado no rio Paraguai, avaliaram às características antiincrustantes do vidro (cerâmico), aço inoxidável, alumínio, aço carbono, zinco, cobre, latão, polietileno, polipropileno, poliuretano, PET, PVC e teflon. Experimentos semelhantes foram realizados com corpos de prova revestidos com tintas a base de óxidos de cobre e zinco na Usina Hidrelétrica de Jaciretá, no rio Paraná (Caprari e Lecot 2001). Caprari (2006) apresenta uma revisão sobre os fundamentos para a realização de experimentos com tintas antiincrustantes visando o controle de incrustações do mexilhão dourado.

Este trabalho teve por objetivo desenvolver soluções via seleção de materiais e engenharia de superfícies (revestimentos) para o controle de incrustações do mexilhão dourado sobre os materiais, como subsídio para o controle populacional desta invasora em hidrelétricas, estações de tratamento de água e embarcações.

\section{Material e Métodos}

Com a finalidade de avaliar o potencial antiincrustante de materiais e revestimentos para o controle do mexilhão dourado foram realizados dois experimentos em dois ambientes aquáticos distintos (Figura 1): (1), no Canal do Jacuí (CJ), principal distributário do delta do rio Jacuí (CJ), bacia do baixo rio Jacuí, na margem direita junto a Ilha da Pintada, situada no município de Porto Alegre, Rio Grande do Sul (Figura 1A); (2) junto ao paredão do barramento do rio Tietê no reservatório da UHE Ibitinga (UI), na bacia do médio rio Tietê-Jacaré, município de Ibitinga, São Paulo (Figura 1B).

O canal do rio Jacuí foi escolhido por apresentar uma população bem estabelecida da espécie invasora, com padrões conhecidos de produção larval e recrutamento (Darrigran e Mansur, 2006; Soares et al., 2008). O segundo local foi escolhido pelo grande número de unidades geradoras de energia, com problemas documentados de bioincrustação e prejuízos econômicos (Filippo, 2004; Darrigran e Mansur, 2006; Pareschi et al., 2008).

Com a finalidade obter dados sobre a produção larval na área de estudo foram obtidas amostras de larvas durante o experimento (outubro de 2006 a fevereiro de 


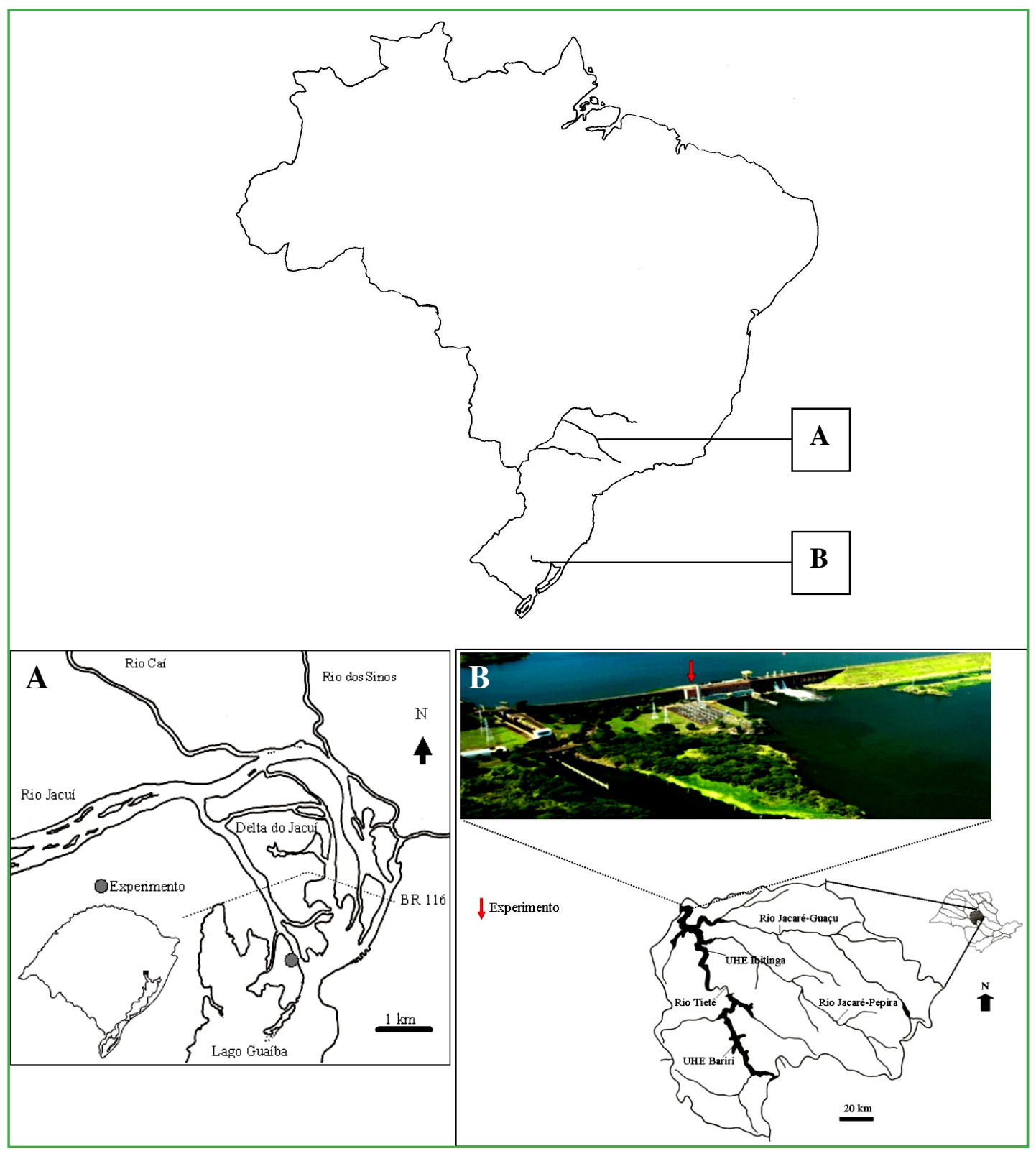

FIGURA 1: Localização dos experimentos: A, no Canal do Jacuí (CJ), junto a Ilha da Pintada, município de Porto Alegre, RS (3000’48,29”S; $51^{\circ} 15^{\prime} 36,46^{\prime \prime} \mathrm{W}$ e altitude de $\left.6,70 \mathrm{~m}\right)$, B, no paredão no reservatório da UHE Ibitinga (UI), bacia do médio rio Tietê-Jacaré, Ibitinga, SP (2145’26,05”S e 4959’30,11”W e altitude de 398m). Mapa adaptado de Tundisi et al. (2008).

2007, no CJ; outubro de 2006 e fevereiro de 2007 na UI). Para tal foram filtradas em rede de $30 \mu \mathrm{m} 100 \mathrm{~L}$ de água. A determinação e quantificação do material seguiram Santos et al. (2005).

Os corpos de prova permaneceram submersos por 120 dias durante os meses de outubro (2006) a fevereiro (2007). O período para a realização dos experimentos foi escolhido por ser a época de maior produção larval e recrutamento, conforme dados históricos do rio Paraná
(Boltovskoy e Cataldo, 1999), lago Guaíba e delta do rio Jacuí (Santos et al., 2008; Bergonci et al., 2009; Mansur et al., 2009). O tempo de duração do experimento (120 dias) corresponde ao necessário e suficiente para que ocorra o recrutamento nos corpos de prova (substrato artificial) com a formação de aglomerados (Bergonci et al., 2009; Mansur et al., 2009).

Os corpos de prova foram construídos na forma placas retangulares com $21 \mathrm{~cm}$ de comprimento e $6 \mathrm{~cm}$ de 
largura. A espessura foi de um centímetro para o material cerâmico e $0,3 \mathrm{~cm}$ para o metálico. Seis réplicas de cada material com ou sem revestimento foram testadas in loco. Os materiais e revestimentos testados encontramse discriminados na Tabela 1. No aço carbono e na cerâmica foram testados três tipos de revestimentos: tinta esmalte (TE) de acabamento bicomponente epóxi brilhante, curada com poliamina, adicionadas com óxidos de cobre e zinco (nanométricos e convencionais); tinta $\mathrm{R}$ comercial e tinta antibactérias comercial. A tinta TE tem seu uso recomendado no acabamento e proteção de substratos expostos aos ambientes severos e quimicamente corrosivos. Também é comumente utilizada para a pintura de equipamentos e estruturas metálicas em geral.

O material cerâmico foi escolhido para o teste de revestimentos devido a sua ampla utilização como substrato artificial no monitoramento do mexilhão dourado no sul do Brasil (Santos et al., 2008; Soares et al., 2008; Bergonci et al., 2009), gerando uma série consistente de dados sobre o recrutamento e desenvolvimento de incrustações neste tipo de material. Este substrato é praticamente inerte e devido a sua alta porosidade favorece a colonização pela invasora (Bergonci et al., 2009). Desta forma o padrão de recrutamento em material cerâmico constitui um parâmetro adequado para a avaliação de materiais e revestimentos.

Os corpos de prova foram fixados aleatoriamente em estruturas metálicas denominadas bastidores por Caprari (2006) (Figura 2). Nas margens do CJ, os bastidores foram submersos sob trapiches construídos para tal finalidade. Já na UI, os bastidores foram fixados junto ao paredão do barramento do reservatório.

Após a retirada dos corpos de prova da água, estes foram secos em forno de Pasteur a $60^{\circ} \mathrm{C}$ e depois quantificados sob estereomicroscópio. Para a quantificação dos mexilhões (ind. $\mathrm{cm}^{-2}$ ) foi utilizado o método descrito em Bergonci et al. (2009), com as seguintes modificações (Figura 3): com a finalidade de eliminar o efeito de borda junto às extremidades do corpo de prova, onde foram inseridas as anilhas de fixação dos mesmos aos bastidores metálicos, foram considerados e quantificados apenas os organismos fixados sobre a área $\left(42 \mathrm{~cm}^{2}\right)$ do segmento central $\left(\mathrm{S}_{\mathrm{II}}\right)$; para abundâncias $<100$ ind./segmento foi realizada a quantificação total do segmento; para abundâncias $>100$ ind./segmento foi realizada a subamostragem por quadrículas.

TABELA 1: Materiais e revestimentos testados. Tinta esmalte(TE)deacabamentobiocomponente epóxi brilhante, curada com poliamina.

\begin{tabular}{|c|c|c|}
\hline Material & Revestimento & Código \\
\hline \multirow{5}{*}{$\begin{array}{l}\text { 1. Aço } \\
\text { galvanizado }\end{array}$} & 1.1 Isento & $\mathrm{AG}$ \\
\hline & 2.1 Isento & Aço \\
\hline & 2.2 TE sem óxidos & APSO \\
\hline & $\begin{array}{l}2.3 \mathrm{TE}+\text { óxido de zinco } \\
\text { nanométrico } 5 \%\end{array}$ & AZnOnano \\
\hline & $\begin{array}{l}2.4 \mathrm{TE}+\text { óxido de zinco } \\
\text { convencional } 5 \%\end{array}$ & AZnOcom \\
\hline \multirow[t]{4}{*}{$\begin{array}{l}\text { 2. Aço } \\
\text { carbono }\end{array}$} & $\begin{array}{l}2.5 \mathrm{TE}+\text { óxido de cobre } \\
\text { nanométrico } 5 \%\end{array}$ & $\mathrm{ACu}_{2}$ Onano \\
\hline & $\begin{array}{l}2.6 \mathrm{TE}+\text { óxido de cobre } \\
\text { convencional } 5 \%\end{array}$ & $\mathrm{ACu}_{2} \mathrm{Ocom}$ \\
\hline & 2.7 Tinta $\mathrm{R}$ comercial & ATR \\
\hline & $\begin{array}{l}2.8 \text { Tinta antibactérias co- } \\
\text { mercial }\end{array}$ & $\mathrm{ABac}$ \\
\hline \multirow[t]{4}{*}{$\begin{array}{l}\text { 3. Aço } \\
\text { cobreado }\end{array}$} & & Pc \\
\hline & 4.1 Isento & Cer \\
\hline & 4.2 TE sem óxidos & CPSO \\
\hline & $\begin{array}{l}4.3 \mathrm{TE}+\text { óxido de zinco } \\
\text { nanométrico } 5 \%\end{array}$ & CZnOnano \\
\hline \multirow[t]{3}{*}{ 4. Cerâmica } & $\begin{array}{l}4.4 \mathrm{TE}+\text { óxido de zinco } \\
\text { convencional } 5 \%\end{array}$ & CZnOcom \\
\hline & $\begin{array}{l}4.5 \mathrm{TE}+\text { óxido de cobre } \\
\text { nanométrico } 5 \%\end{array}$ & $\mathrm{CCu}_{2}$ Onano \\
\hline & $\begin{array}{l}4.6 \mathrm{TE}+\text { óxido de cobre } \\
\text { convencional } 5 \%\end{array}$ & $\mathrm{CCu}_{2} \mathrm{Ocom}$ \\
\hline
\end{tabular}

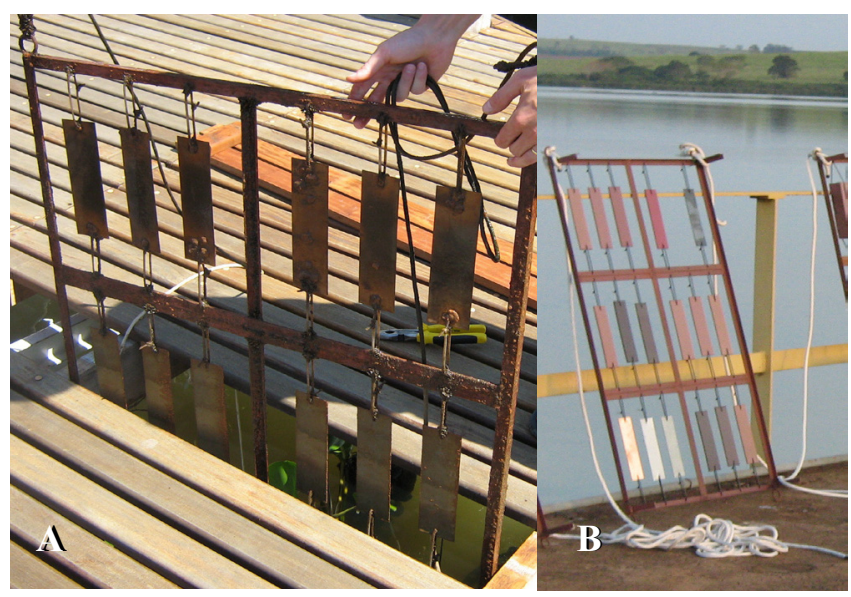

FIGURA 2: Bastidores de ferro contendo corpos: (A) sendo submerso sob trapiche de madeira, na margem direita do Canal do Jacuí (CJ), RS; (B) pronto para a submersão na UHE Ibitinga, SP. 


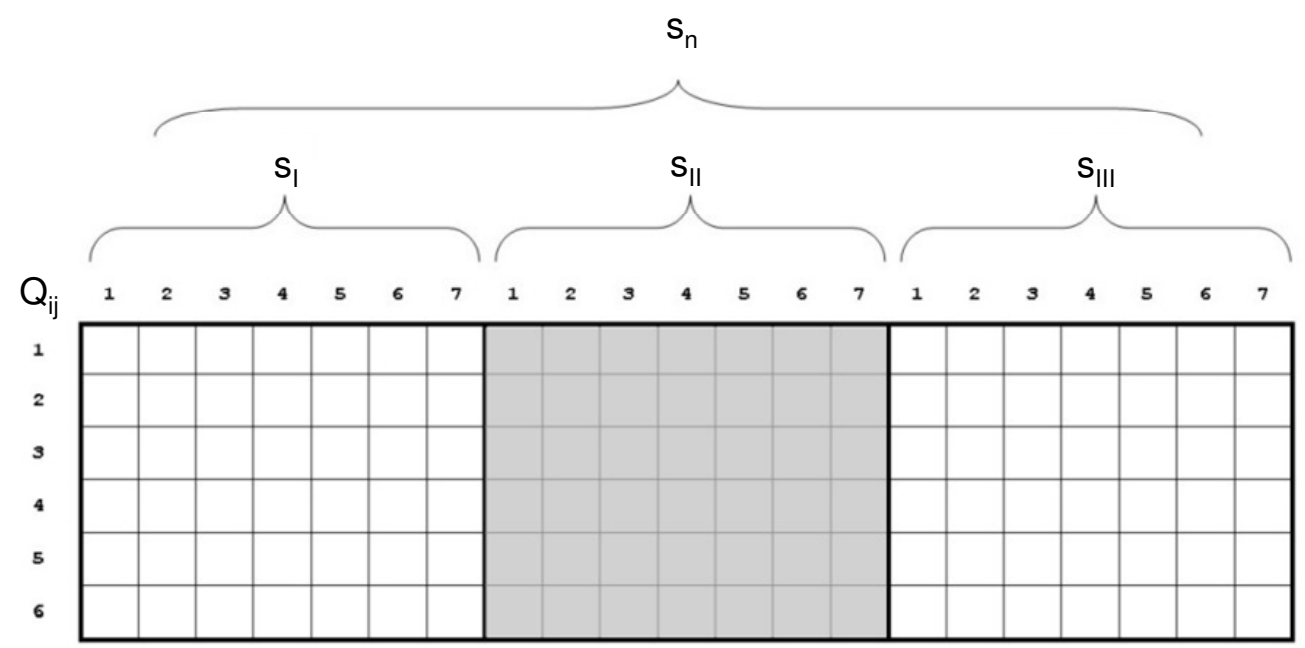

FIGURA 3: Malha quadriculada utilizada para a contagem de mexilhões aderidos aos corpos de prova conforme método adaptado de Bergonci et al. (2009). Área considerada para a quantificação em cinza $\left(\mathrm{S}_{\mathrm{II}}\right)$.

As modificações na superfície foram avaliadas qualitativamente (presença e ausência) através de estereomicroscopia (Olympus SZX7), considerando-se o percentual de ocorrência de biofilmes de briozoários, biofilmes de algas, raízes de água-pé, deposição de algas do hipolímnio, deterioração do revestimento, corrosão e aderência de detritos nos segmentos dos corpos de prova.

Com base nos dados logaritimizados, $\mathrm{LOG}(\mathrm{x}+1)$, de densidade média de mexilhão dourado, aplicou-se à análise de variância ANOVA com nível de significância de $95 \%$ seguida de múltiplas comparações pelo método de Duncan $(\mathrm{p}=0,05)$, com o auxílio do pacote estatístico SPSS 11.5. A ANOVA foi empregada após a constatação da normalidade dos dados anormalidade dos dados, obtida através do teste Kolmogorv-Smirnov para uma amostra (H0: dados seguem a distribuição normal), com nível de significância de $95 \%(\alpha=0,05)$. A correlação não paramétrica (Spearman's rho) entre a densidade do mexilhão dourado e o percentual de ocorrência de modificações na superfície dos corpos de prova (distribuição não normal) foi realizada através pacote estatístico SPSS 11.5. A ordenação dos materiais e revestimentos com base na densidade do mexilhão dourado e modificações na superfície dos corpos de prova foi realizada através da análise de componentes principais (ACP), com base em matriz de correlação entre variáveis, com auxílio do pacote estatístico PCORD 4.10. Todos os procedimentos estatísticos estão de acordo com Zar (1999) e Valentin (2000).

\section{Resultados}

\section{Densidade larval}

A densidade de larvas (ind. $\mathrm{m}^{-3}$ ) no $\mathrm{CJ}$ foi mais elevada em outubro de 2006 (Figura 4), no início do experimento, e menor em fevereiro de 2007, no final do experimento. Os valores de densidade larval na UI, no momento da submersão dos corpos e na retirada dos mesmos, foram semelhantes: 110 e 113 ind. $\mathrm{m}^{-3}$.

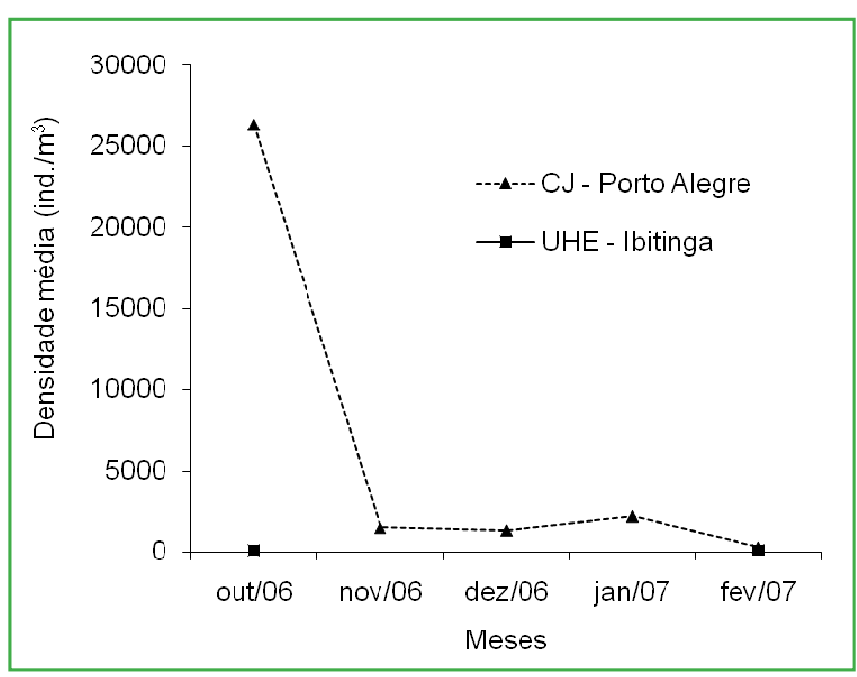

FIGURA 4: Densidade larval do mexilhão dourado no Canal do Jacuí (CJ), Porto Alegre, RS, e na UHE Ibitinga (UI), Ibitinga, SP. 


\section{Colonização sobre o aço}

Os valores médios, erro padrão, mínimo e máximo da densidade de mexilhões aderidos aos corpos de prova de aço submersos no CJ estão discriminados na Figura 5. De acordo com a análise de variância ANOVA $\left(\mathrm{F}_{\text {calc }}=\right.$ 72,550; $\mathrm{p}<0,001)$ seguida de teste de Duncan, com base nas densidades do mexilhão dourado nos corpos de prova testados no CJ, formaram-se quatro grupos distintos (Figura 5) denominados G1 a G4: num extremo o grupo G1 (p $=0,99$ ) formado por aço carbono revestido com tinta $\mathrm{R}$, aço cobreado, aço carbono revestido com revestimento antibactérias comercial e aço galvanizado (corpos de prova que apresentaram menor densidade do molusco); e noutro, o G4 ( $\mathrm{p}=0,11)$ formado apenas por aço carbono revestido com tinta base sem óxidos (corpos de prova que apresentaram maior densidade). Dentre estes dois grupos, estão os matérias e revestimentos que apresentaram densidade intermediária $(\mathrm{G} 2, \mathrm{p}=1,00 ; \mathrm{G} 3, \mathrm{p}=0,07)$.

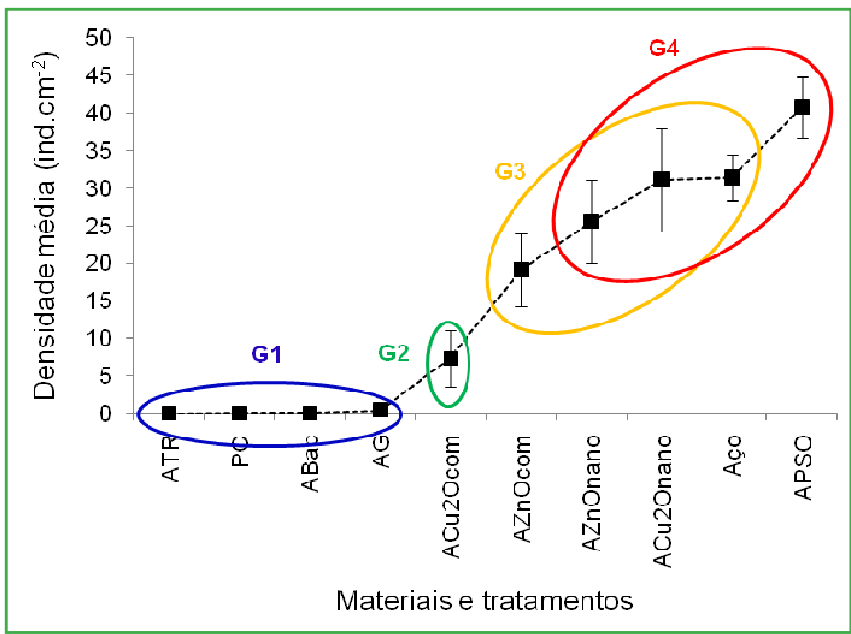

FIGURA 5: Densidade média (ind. $\mathrm{cm}^{-2}$ ) do mexilhão dourado em carbono, com e sem revestimento, testado no Canal do Jacuí (CJ), Porto Alegre, RS. Grupos formados segundo a ANOVA (Duncan a posteriori): G1 a G4. Aço galvanizado (AG), Aço carbono sem revestimento (Aço), Aço + TE sem óxidos (APSO), Aço + TE + óxido de zinco nanométrico 5\% (AZnOnano), Aço + TE + óxido de zinco convencional 5\% (AZnOcom), Aço + TE + óxido de cobre nanométrico 5\% (ACu2Onano), Aço $+\mathrm{TE}+$ óxido de cobre convencional 5\% (ACu2Ocom), Aço + Tinta R comercial (ATR), Aço + Tinta antibactérias comercial (ABac), Aço cobreado (PC).

Os valores médios, erro padrão, mínimo e máximo da densidade de mexilhões aderidos aos corpos de prova de aço submersos na UI estão discriminados na Figura
6. De acordo com a ANOVA as placas submersas na UI diferiram entre si $\left(\mathrm{F}_{\text {calc }}=31,428 ; \mathrm{p}<0,001\right)$. Segundo o teste de Duncan a posteriori $(\alpha=0,05)$ houve a discriminação de cinco grupos (Figura 6) denominados G1 a G5: num extremo o grupo G1 $(\mathrm{p}=0,98)$ formado por aço galvanizado e aço carbono revestido com tinta $\mathrm{R}$, enquanto que o grupo G5 ( $\mathrm{p}=0,85)$, formado apenas por aço carbono revestido com óxido de zinco convencional. Dentre estes dois grupos, estão os materiais e revestimentos que apresentaram densidade intermediária (G2, p=0,09; G3, p=0,09; G4, p=0,08). Da mesma forma como nos resultados observados para o CJ, o aço galvanizado e aço carbono revestido com a tinta $\mathrm{R}$ foram os de melhor resultado antiincrustante.

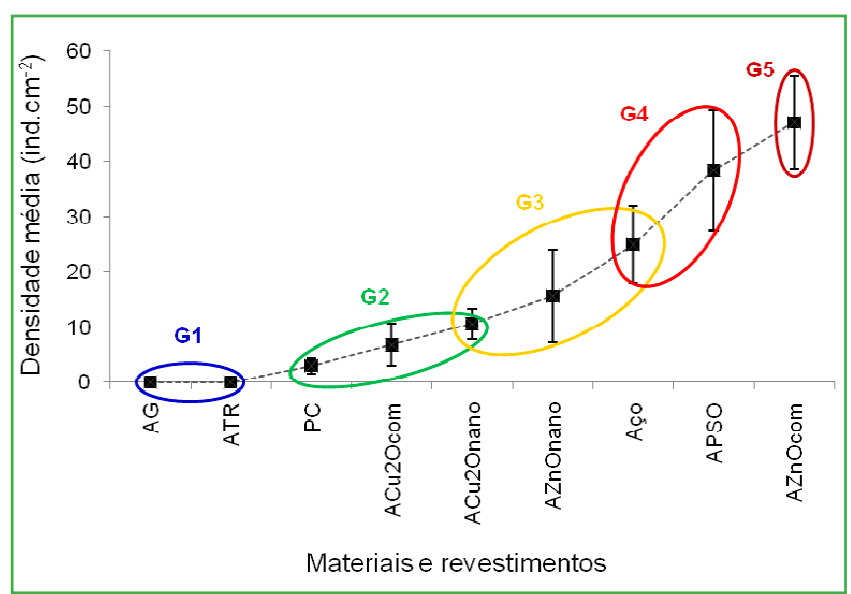

FIGURA 6: Densidade média (ind. $\mathrm{cm}^{-2}$ ) de mexilhão dourado incrustado em aço carbono, com e sem revestimento, testado na UHE Ibitinga (UI), Ibitinga, SP. Grupos formados segundo a ANOVA (Duncan a posteriori): G1 a G5. Aço galvanizado (AG), Aço carbono sem revestimento (Aço), Aço + Tinta esmalte (TE) de acabamento biocomponente epóxi brilhante, curada com poliamina, sem óxidos (APSO), Aço + TE + óxido de zinco nanométrico 5\% (AZnOnano), Aço + TE + óxido de zinco convencional 5\% (AZnOcom), Aço + TE + óxido de cobre nanométrico 5\% (ACu2Onano), Aço + $\mathrm{TE}+$ óxido de cobre convencional 5\% (ACu2Ocom), Aço + Tinta R comercial (ATR), Aço + Tinta antibactérias comercial (ABac), Aço cobreado (PC).

\section{Colonização da cerâmica}

Os valores médios, erro padrão, mínimo e máximo da densidade de mexilhões aderidos aos corpos de prova cerâmicos submersos no CJ estão na Figura 7.

A ANOVA $\left(\mathrm{F}_{\text {calc }}=2,759 ; \mathrm{p}=0,025\right)$ seguida de múltiplas comparações pelo método de Duncan apontou 
para a diferenciação dos revestimentos em dois grupos (Figura 7) denominados G1 e G2: o grupo G1 (p = $0,44)$ por $\mathrm{ZnO}$ convencional, $\mathrm{Cu}_{2} \mathrm{O}$ nanométrico e $\mathrm{Cu}_{2} \mathrm{O}$ convencional (menor populacional); o grupo $\mathrm{G} 2$ (p $=0,08)$ por $\mathrm{Cu}_{2} \mathrm{O}$ nanométrico e $\mathrm{Cu}_{2} \mathrm{O}$ convencional e tijoleta com revestimentos sem óxidos (densidade populacional intermediária); e o terceiro, composto por tijoleta com revestimentos sem óxidos, $\mathrm{ZnO}$ nanométrico e tijoleta sem revestimento (maior densidade). O revestimento de melhor resultado foi o $\mathrm{ZnO}$ convencional, apresentando uma densidade média $(25,06 \pm 3,00$ ind. $\left.\mathrm{cm}^{-2}\right)$ consideravelmente inferior à observada no substrato cerâmico sem revestimento $\left(45,22 \pm 3,00\right.$ ind. $\left.\mathrm{cm}^{-2}\right)$.

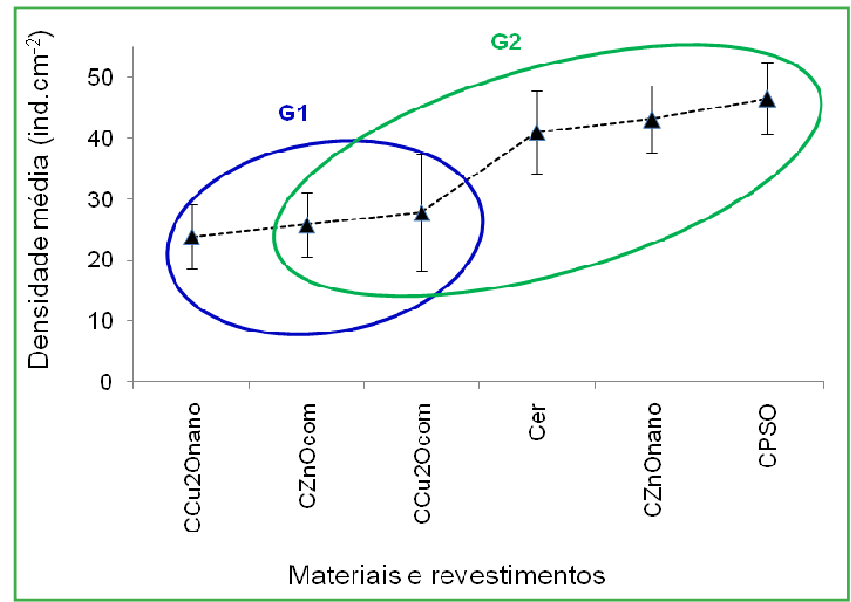

FIGURA 7: Densidade média (ind. $\mathrm{cm}^{-2}$ ) do mexilhão dourado incrustado em cerâmica, com e sem revestimento, testada no Canal do Jacuí, Porto Alegre, RS. Os círculos coloridos representam os agrupamentos formados segundo a ANOVA (Duncan a posteriori): G1 e G2. Cerâmica sem revestimento (Cer), Cerâmica + TE sem óxidos (CPSO), Cerâmica com Tinta esmalte (TE) de acabamento biocomponente epóxi brilhante, curada com poliamina + óxido de zinco nanométrico 5\% (CZnOnano), Cerâmica com TE + óxido de zinco convencional 5\% (CZnOcom), Cerâmica com TE + óxido de cobre nanométrico 5\% (CCu2Onano), Cerâmica com TE + óxido de cobre convencional 5\% (CCu2Ocom).

Os valores médios, erro padrão, mínimo e máximo da densidade de mexilhões aderidos aos corpos de prova cerâmicos submersos na UI estão na Figura 8.

Diferenças significativas não foram observadas entre os tratamentos (ANOVA: $\mathrm{F}_{\text {calc }}=1,881 ; \mathrm{p}=0,108$ ). De maneira semelhante ao constatado para os corpos de prova em aço carbono, os revestimentos testados sobre o substrato cerâmico também apresentaram deterioração, provavelmente, pelas características da água do reservatório.

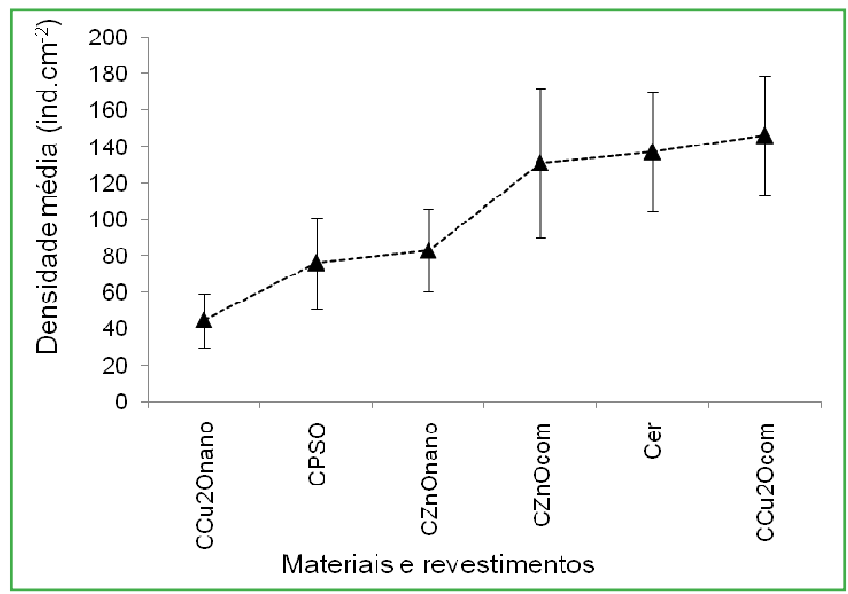

FIGURA 8: Densidade média (ind. $\mathrm{cm}^{-2}$ ) do mexilhão dourado incrustado em cerâmica, com e sem revestimento, testada na UHE Ibitinga, Ibitinga, SP. Cerâmica sem revestimento (Cer), Cerâmic + TE sem óxidos (CPSO), Cerâmica com Tinta esmalte (TE) de acabamento biocomponente epóxi brilhante, curada com poliamina + óxido de zinco nanométrico $5 \%$ (CZnOnano), Cerâmica com TE + óxido de zinco convencional 5\% (CZnOcom), Cerâmica com TE + óxido de cobre nanométrico 5\% (CCu2Onano), Cerâmica com TE + óxido de cobre convencional 5\% (CCu2Ocom).

\section{Modificações na superfície dos corpos de prova}

Nos materiais testados no CJ e na UI foram detectados diferentes tipos de biofilmes e alterações na superfície decorrentes de corrosão (Figura 9 e 10). O percentual da área de cobertura de biofilmes e das modificações na superfície dos corpos de prova submergidos no CJ e UI encontra-se discriminados na Tabela 2. No Canal do Jacuí as densidades de mexilhão dourado apresentaram correlação positiva e significativa com a ocorrência de Bryozoa $(\rho=0,526 ; p=0,04)$. $\mathrm{Na}$ UHE Ibitinga as densidades de mexilhão dourado apresentaram correlação positiva e significativa com a ocorrência de Bryozoa $(\rho=0,939 ; p \leq 0,01)$; correlação positiva e significativa com a ocorrência de algas perifíticas $(\rho=0,778 ; p \leq 0,01)$ e negativa e significativa com corrosão do material $(\rho=-0,741 ; p \leq 0,01)$.

Através da Análise de Componentes Principais (Figura 11$)$, os eixos $1(38,99 \%)$ e $2(22,72 \%)$ 
sumarizaram $61,72 \%$ da variabilidade total dos dados de densidades do mexilhão dourado e percentual de ocorrência das modificações nas superfícies dos corpos de prova testados. Pela ordenação dos eixos observouse a formação de cinco grupos (G1 a G5) de materiais. O grupo 1 ordenou os corpos de prova cerâmicos com seus respectivos revestimentos testados no Canal do Jacuí. O grupo 2 ordenou os corpos de prova em aço, com seus respectivos revestimentos testados no Canal do Jacuí e os corpos de prova em aço revestido com a tinta $\mathrm{R}$ comercial, que foram testados na UHE Ibitinga. O grupo 3 ordenou os corpos de prova em aço com óxido de zinco convencional e aço com revestimento sem óxidos. O grupo 4 ordenou os corpos de prova cerâmicos com seus respectivos revestimentos testados na UHE Ibitinga. O grupo 5 ordenou os demais corpos de prova metálicos e respectivos revestimentos testados na UHE Ibitinga.

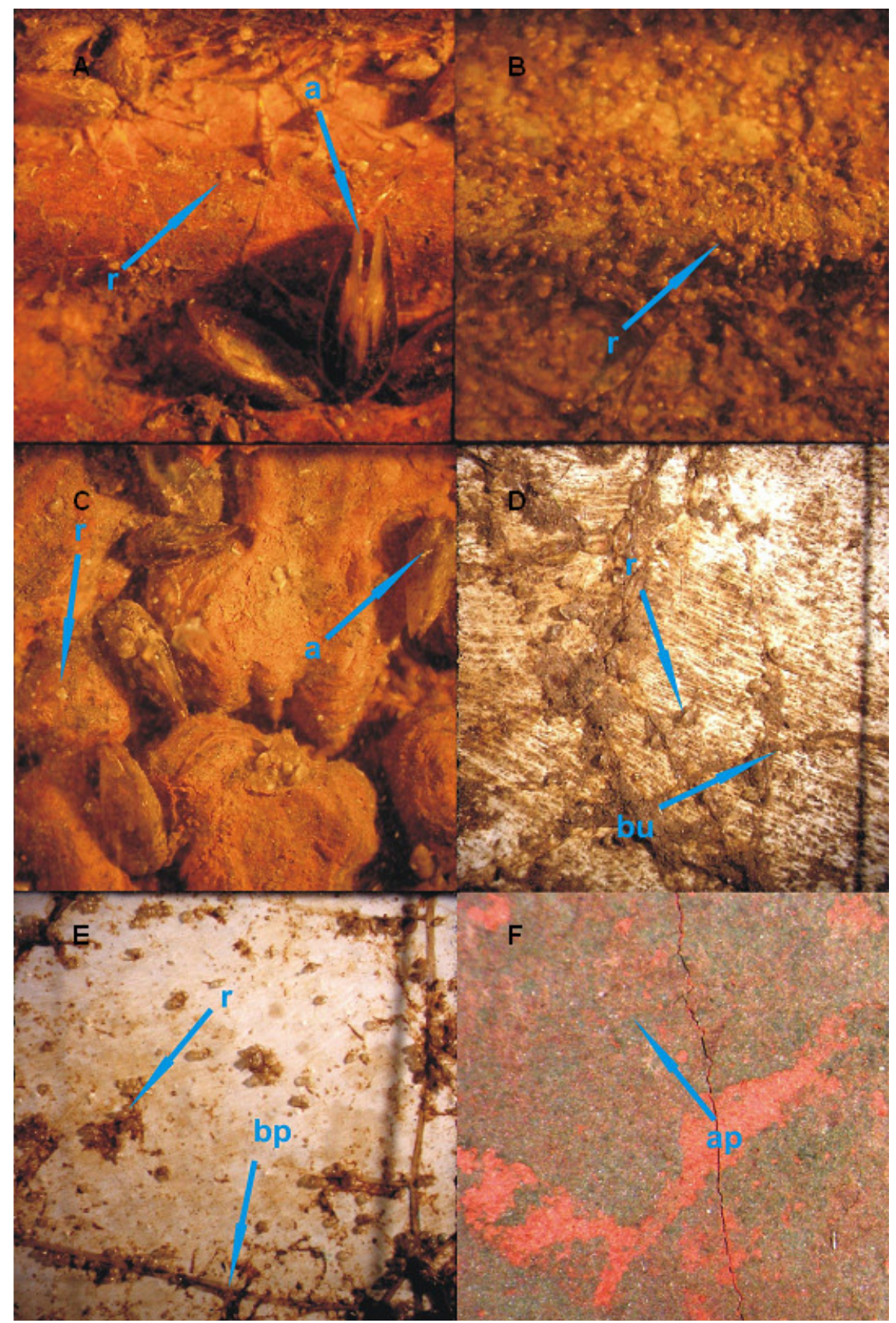

FIGURA 9: Modificações na superfície dos corpos de prova: cerâmica sem revestimento (A e B); aço carbono sem revestimento (C); aço carbono com revestimento de óxido de zinco nanométrico (D); aço carbono com revestimento de óxido de cobre nanométrico (E), aço carbono com tinta R (F); adultos (a); algas perifíticas (ap); briozoários com morfologia semelhante a Urnatella gracilis (bu) e similar a Plumatella spp. (bp); recrutas (r). 


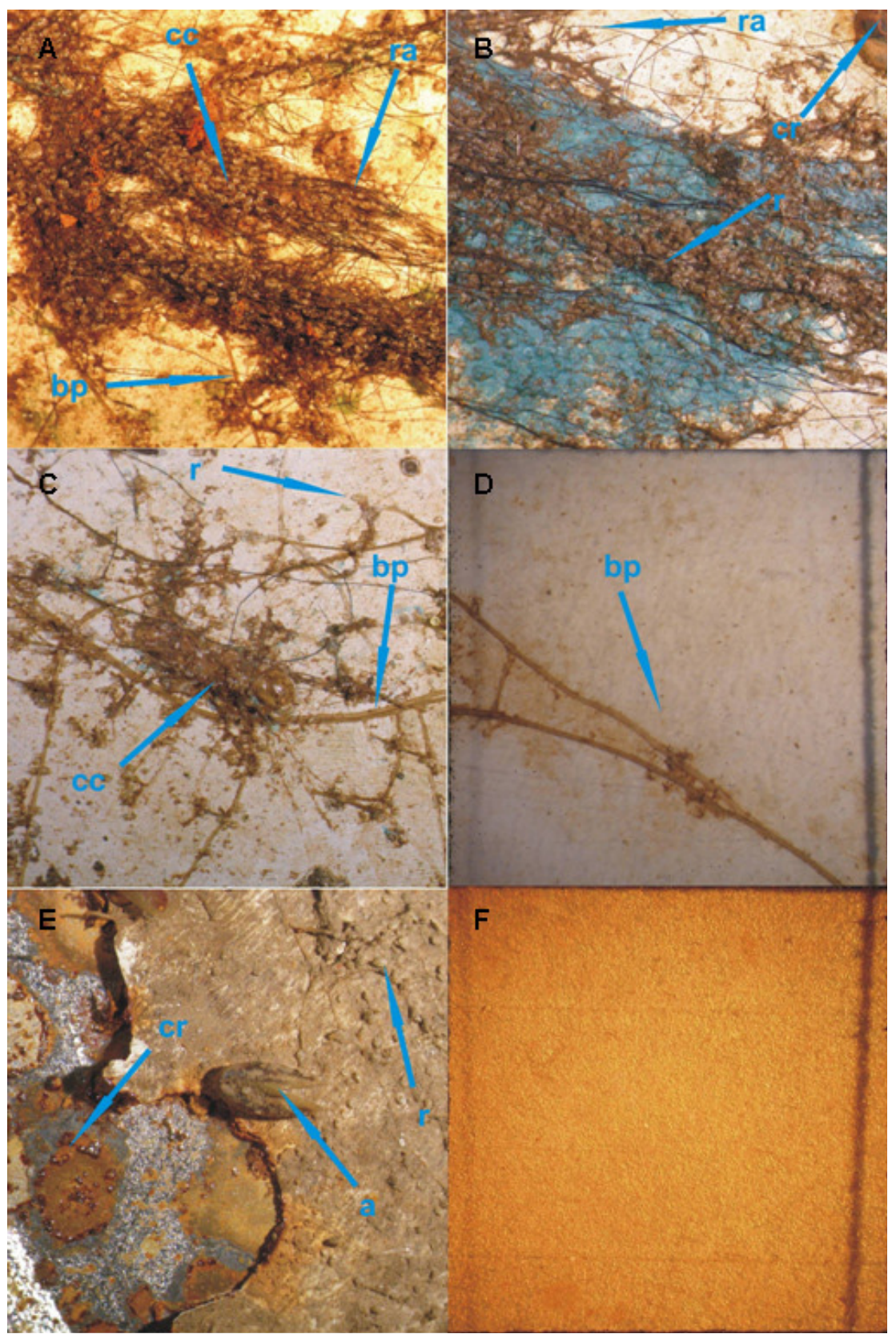

FIGURA 10: Biofilmes e alterações na superfície dos corpos de prova. Cerâmico com revestimento de com óxido de zinco comercial (A); cerâmico com revestimento de com óxido de zinco nanométrico (B); cerâmico com revestimento sem óxidos (C); aço carbono com revestimento antibactérias (D); aço carbono com revestimento de óxido de zinco nanométrico (E); aço cobreado sem incrustações (F); adultos (a); briozoário com morfologia semelhante a Plumatella spp. (bp); casulo de chironomidae (cc); corrosão (cr); raízes de água pé (ra); recrutas (r). 
TABELA 2: Modificações na superfície (\% de área) dos corpos de prova testados no Canal do Jacuí (RS) e UHE Ibitinga (SP). Deterioração do revestimento (DRev), corrosão (Cor), biofilme de algas perifíticas (Per), biofilme de briozoários (Bry), depósitos de detritos (Det), depósitos de algas do hipolímio (Alh) e deposito de raízes de água pé (ChRa). Aço galvanizado (AG), Aço carbono sem revestimento (Aço), Aço + com Tinta esmalte (TE) de acabamento biocomponente epóxi brilhante, curada com poliamina, sem óxidos (APSO), Aço + TE + óxido de zinco nanométrico 5\% (AZnOnano), Aço + TE + óxido de zinco convencional 5\% (AZnOcom), Aço + TE + óxido de cobre nanométrico 5\% (ACu2Onano), Aço + TE + óxido de cobre convencional 5\% (ACu2Ocom), Aço + Tinta R comercial (ATR), Aço + Tinta antibactérias comercial (ABac), Aço cobreado (Pc), Cerâmica sem revestimento (Cer), Cerâmica $+\mathrm{TE}$ sem óxidos (CPSO), Cerâmica com TE + óxido de zinco nanométrico 5\% (CZnOnano), Cerâmica com $\mathrm{TE}+$ óxido de zinco convencional 5\% (CZnOcom), Cerâmica com TE + óxido de cobre nanométrico 5\% (CCu2Onano), Cerâmica com TE + óxido de cobre convencional 5\% (CCu2Ocom).

\begin{tabular}{|c|c|c|c|c|c|c|c|}
\hline \multirow{2}{*}{ Materias/Revestimentos } & \multicolumn{7}{|c|}{ Alterações } \\
\hline & DRev & Cor & Per & Bry & Det & Alh & ChRa \\
\hline \multicolumn{8}{|l|}{ Canal do Jacuí, RS } \\
\hline Cer & 0,0 & 0,0 & 2,8 & 91,7 & 66,7 & 0,0 & 0,0 \\
\hline CPSO & 0,0 & 0,0 & 38,9 & 88,9 & 91,7 & 0,0 & 0,0 \\
\hline CZnOnano & 0,0 & 0,0 & 0,0 & 86,1 & 100,0 & 0,0 & 0,0 \\
\hline CZnOcom & 0,0 & 0,0 & 0,0 & 91,7 & 100,0 & 0,0 & 0,0 \\
\hline CCuOnano & 0,0 & 0,0 & 91,7 & 86,1 & 100,0 & 0,0 & 0,0 \\
\hline CCuOcom & 0,0 & 0,0 & 97,2 & 86,1 & 100,0 & 0,0 & 0,0 \\
\hline Aço & 0,0 & 91,7 & 16,7 & 0,0 & 22,2 & 0,0 & 0,0 \\
\hline APSO & 5,6 & 83,3 & 100,0 & 100,0 & 0,0 & 0,0 & 0,0 \\
\hline AZnOnano & 0,0 & 100,0 & 91,7 & 8,3 & 47,2 & 0,0 & 0,0 \\
\hline AZnOcom & 25,0 & 8,3 & 100,0 & 97,2 & 2,8 & 0,0 & 0,0 \\
\hline ACuOnano & 61,1 & 91,7 & 38,9 & 16,7 & 0,0 & 0,0 & 0,0 \\
\hline ACuOcom & 61,1 & 100,0 & 77,8 & 80,6 & 0,0 & 0,0 & 0,0 \\
\hline ATR & 1,9 & 1,9 & 94,4 & 0,0 & 0,0 & 0,0 & 0,0 \\
\hline Abac & 0,0 & 0,0 & 83,3 & 58,3 & 0,0 & 0,0 & 0,0 \\
\hline $\mathrm{AG}$ & 0,0 & 83,3 & 0,0 & 2,8 & 0,0 & 0,0 & 0,0 \\
\hline $\mathrm{PC}$ & 0,0 & 72,2 & 0,0 & 0,0 & 8,3 & 0,0 & 0,0 \\
\hline \multicolumn{8}{|l|}{ UHE Ibitinga, SP } \\
\hline Cer & 0,0 & 0,0 & 63,9 & 88,9 & 77,8 & 72,2 & 86,1 \\
\hline CPSO & 0,0 & 0,0 & 83,3 & 80,6 & 41,7 & 11,1 & 55,6 \\
\hline CZnOcom & 0,0 & 0,0 & 100,0 & 91,7 & 8,3 & 47,2 & 94,4 \\
\hline CZnOnano & 0,0 & 0,0 & 91,7 & 83,3 & 0,0 & 44,4 & 75,0 \\
\hline CCuOcom & 0,0 & 0,0 & 83,3 & 94,4 & 91,7 & 38,9 & 91,7 \\
\hline CCuOnano & 0,0 & 0,0 & 72,2 & 75,0 & 83,3 & 22,2 & 77,8 \\
\hline Aço & 0,0 & 100,0 & 11,1 & 0,0 & 38,9 & 2,8 & 69,4 \\
\hline APSO & 88,9 & 47,2 & 47,2 & 55,6 & 61,1 & 86,1 & 0,0 \\
\hline AZnOcom & 58,3 & 50,0 & 50,0 & 41,7 & 38,9 & 44,4 & 52,8 \\
\hline AZnOnano & 44,4 & 44,4 & 41,7 & 33,3 & 22,2 & 19,4 & 58,3 \\
\hline ACuOcom & 100,0 & 100,0 & 47,2 & 16,7 & 2,8 & 36,1 & 80,6 \\
\hline ACuOnano & 97,2 & 97,2 & 61,1 & 25,0 & 30,6 & 86,1 & 69,4 \\
\hline ATR & 0,0 & 1,9 & 14,8 & 0,0 & 7,4 & 7,4 & 27,8 \\
\hline AG & 0,0 & 86,1 & 47,2 & 0,0 & 61,1 & 33,3 & 75,0 \\
\hline $\mathrm{PC}$ & 0,0 & 100,0 & 0,0 & 0,0 & 19,4 & 19,4 & 100,0 \\
\hline
\end{tabular}




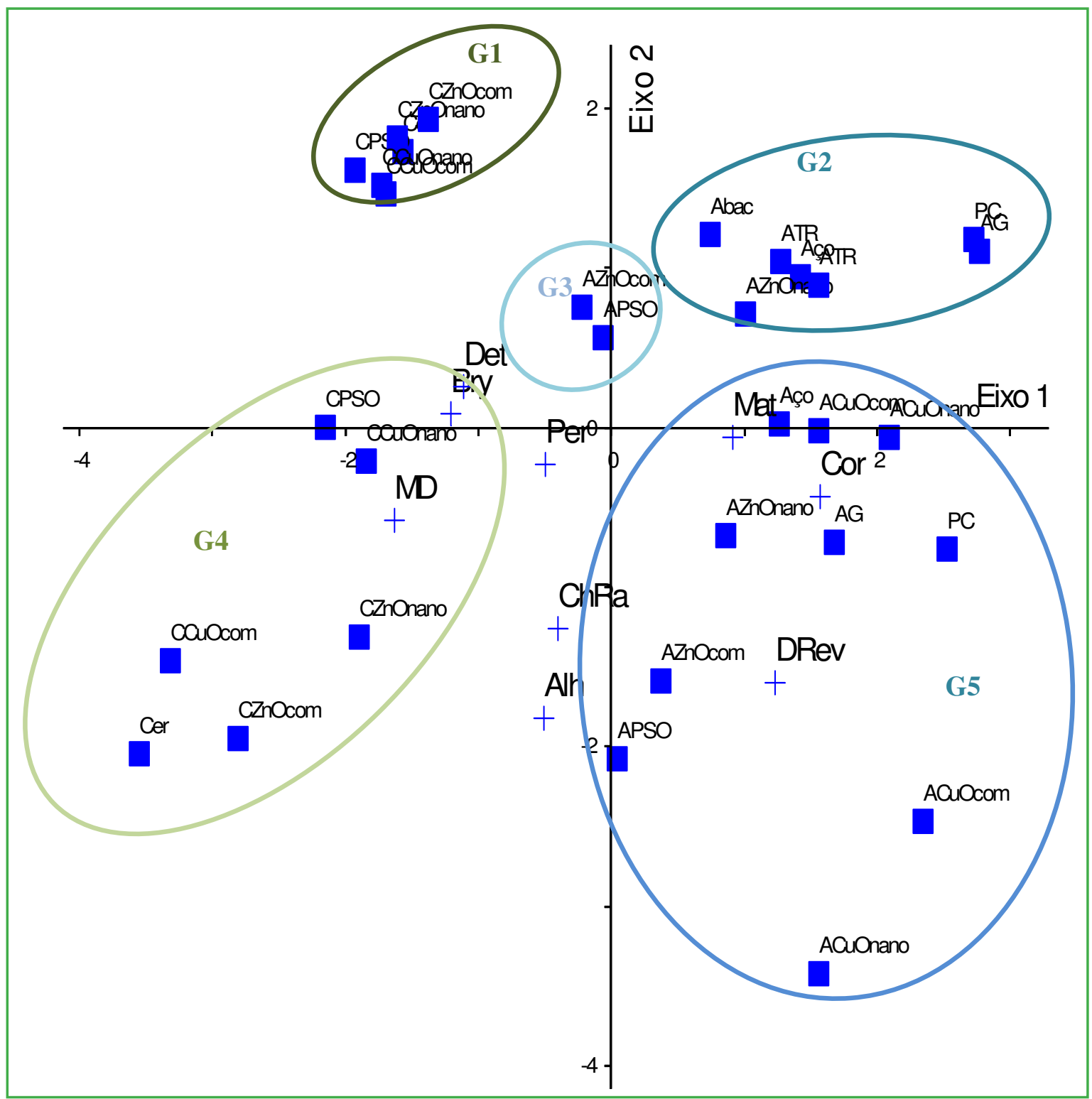

FIGURA 11: Ordenação (ACP) dos materiais e revestimentos, com base na densidade populacional do mexilhão dourado, e relação com as modificações na superfície dos mesmos: experimento realizado no Canal do Jacuí (RS, Brasil). Canal do Jacuí (J); UHE Ibitinga (I). Deterioração do revestimento (DRev), corrosão (Cor), biofilme de algas perifíticas (Per), biofilme de briozoários (Bry), depósitos de detritos (Det), depósitos de algas do hipolímio (Alh) e deposito de raízes de água pé (ChRa). Aço galvanizado (AG), Aço carbono sem revestimento (Aço), Aço + com Tinta esmalte (TE) de acabamento biocomponente epóxi brilhante, curada com poliamina, sem óxidos (APSO), Aço + $\mathrm{TE}+$ óxido de zinco nanométrico 5\% (AZnOnano), Aço + TE + óxido de zinco convencional 5\% (AZnOcom), Aço + TE + óxido de cobre nanométrico 5\% (ACu2Onano), Aço + TE + óxido de cobre convencional 5\% (ACu2Ocom), Aço + Tinta R comercial (ATR), Aço + Tinta antibactérias comercial (ABac), Aço cobreado (Pc), Cerâmica sem revestimento (Cer), Cerâmica + TE sem óxidos (CPSO), Cerâmica com TE + óxido de zinco nanométrico 5\% (CZnOnano), Cerâmica com TE + óxido de zinco convencional 5\% (CZnOcom), Cerâmica com TE + óxido de cobre nanométrico 5\% (CCu2Onano), Cerâmica com TE + óxido de cobre convencional 5\% (CCu2Ocom). 


\section{Discussão}

A eficiência do aço cobreado no controle de bioincrustação pode ser justificada com base nos resultados obtidos por Faria et al. (2006), em experimentos de laboratório e campo. Segundo os autores, os materiais que formam óxidos, como o zinco e o aço cobreado, impediram a fixação do mexilhão dourado, tendo-se constatado, também, a alta mortalidade dos organismos frente a esses óxidos, principalmente para as placas de aço cobreado. Esta informação corrobora os resultados obtidos neste trabalho para os corpos de prova de aço cobreado e de aço galvanizado, que constitui em eletrodeposição metálica de zinco.

Dentre os corpos de prova que apresentaram densidades intermediárias, encontra-se a aço cobreado (no material exposto UI) e o aço carbono revestido com tinta base com $\mathrm{Cu}_{2} \mathrm{O}$ convencional (no material exposto no CJ e na UI). Provavelmente a baixa eficiência deste revestimento pode ser atribuída à solubilidade deste óxido. Conforme Caprari (2006), a solubilidade do óxido cuproso $\left(\mathrm{Cu}_{2} \mathrm{O}\right)$, um dos óxidos mais amplamente utilizados em revestimentos antiincrustantes, é baixa em água doce. Pouco se sabe sobre os mecanismos de solubilização deste óxido em ambientes límnicos, já que seu emprego se restringe ao controle de incrustações pelo mexilhão dourado. Na água do mar, onde a solubilidade deste óxido é alta, tem demonstrado eficiência sobre todos os organismos incrustantes, a exceção das algas.

Ainda dentre os grupos que apresentaram densidades intermediárias, o aço carbono sem revestimento apresentou as altas densidades de mexilhão dourado, discordando das observações realizadas por Faria et al. (2006), que constataram baixa percentagem de organismos fixados em aço carbono. Segundo os autores, a baixa força de desligamento e percentagem de organismos no aço carbono pode ser atribuída à oxidação do material, quando em contato com água.

De acordo com Caprari e Lecot (2001), com base em experimentos de campo, os revestimentos com base em partículas de óxidos de zinco se demonstraram promissores para o controle da fixação do mexilhão dourado sobre superfícies. Em termos percentuais, a diminuição da incrustação foi na ordem de $41,74 \%$, quando comparados os corpos de prova de material cerâmico sem revestimento com o material cerâmico revestido com $\mathrm{ZnO}$ convencional. Bergonci et al. (2009) constataram após 90 dias de exposição de substrato cerâmico, no delta do rio Jacuí, no verão de 2005/2006, valores de densidade média na ordem de 23,75 ind. $\mathrm{cm}^{-2}$. A densidade verificada pelos autores é condizente com a densidade larval máxima observada no período daquele estudo (11067 ind. $\mathrm{m}^{-3}$ ), a qual foi consideravelmente inferior à densidade larval máxima constatada no presente estudo (26343 ind. $\mathrm{m}^{-3}$ ). Densidades similares (38 ind. $\mathrm{cm}^{-2}$ ) de mexilhões dourados aderidos aos substratos cerâmicos foram verificadas por Soares et al. (2008).

Ao compararmos o material cerâmico com os demais materiais metálicos sem revestimento (aço carbono, aço galvanizado, aço cobreado) constatou-se que a cerâmica apresentou as incrustações mais densas. A este fato se atribui à superfície porosa e canaliculada do material cerâmico inerte, que propiciam a colonização pelo mexilhão dourado. Contrariamente, os materiais metálicos apresentam superfície lisa de baixa porosidade e são facilmente oxidados, liberando produtos que apresentam toxicidade ao molusco.

Detritos de raízes de água-pé encontrados sobre as superfícies dos materiais funcionaram como um transporte de recrutas para os corpos de prova. As raízes de água-pé são ótimos substratos para os indivíduos recrutas e adultos do mexilhão dourado e servem como meio de transporte rio acima. O aguapé Eichhornia crassipes possui pecíolos esponjosos ricos em tecido aerenquimatoso, que permitem a sua flutuação, e folhas com a forma de uma "vela" de barco que são impulsionadas pelo vento, até mesmo contracorrente, facilitando a proliferação desta espécie (Palombo e Pereira, 1992) e de organismos associados.

Junto aos detritos de raízes de água pé também se verificou alguns casulos de Chironomidae (Diptera). A ocorrência de Chironomidae sobre os corpos de prova com revestimento à base de óxidos de cobre e zinco corrobora com a ocorrência deste grupo em ecossistemas altamente poluídos por metais. Chironomidae, Oligochaeta e Hirudinea estão entre os organismos mais frequentes da comunidade bentônica 
das margens do rio Tietê, ocorrendo em sedimentos com elevados teores de metais como cobre e zinco, entre outros (Kuhlmann et al., 2000).

Em muitos corpos de prova foram verificados briozoários límnicos que se aderiram à superfície do material. Estes organismos são sésseis, filtradores, coloniais e se fixam nos substratos duros (Mugnai et al., 2010). Os briozoários encontrados apresentam morfologia da colônia semelhante as espécies Urnatella gracilis e Plumatella spp., que foram ilustrados por Marcus (1984). No entanto, o estado de conservação não apropriado do material, devido à especificidade dos métodos aplicados voltados o estudo de materiais e revestimentos, não permitiu o estudo aprofundado dos Bryozoa. Scheer (1945) monitorou a sucessão ecológica em comunidades marinhas incrustantes e verificou que $\mathrm{o}$ assentamento de bryozoa antecede o recrutamento e estabelecimento da população de Mytilus californicus. Segundo o autor, o sucesso do estabelecimento da população desta espécie de Mytilidae acarreta no decaimento da população de briozoários.

Nos experimentos realizados os biofilmes funcionaram como verdadeiros corredores facilitadores para o recrutamento do mexilhão dourado, principalmente nas superfícies mais lisas. O mexilhão tem preferência por superfícies de maior rugosidade e porosidade. Também prefere superfícies com frestas ou canaliculadas, pois apresenta tigmotactismo positivo (Uryu et al., 1996; Santos et al., 2008). Sendo assim, nas superfícies lisas sua incrustação é facilitada quando o material já foi colonizado por outros organismos que alteram a superfície, aumentando a rugosidade do mesmo.

O conhecimento científico sobre os processos de colonização dos materiais com diferentes revestimentos por diferentes táxons de macroinvertebrados aquáticos, especialmente Insecta e Bryozoa, e de algas epifíticas, é de fundamental importância para o entendimento do fenômeno da bioincrustação pelo mexilhão dourado e eficácia dos métodos de controle em superfícies.

A ordenação demonstrou a associação entre a bioincrustação do mexilhão dourado e os corpos de prova cerâmicos, que são preferidos pela invasora. Também demonstrou que as modificações nas superfícies dos materiais e revestimentos tiveram maior influência sobre os corpos de prova testados na UHE Ibitinga.

Outras modificações na superfície como corrosão, deterioração do revestimento e deposição de detritos foram determinantes para o processo de colonização dos corpos de prova. As correlações entre a corrosão do material foram negativas, mas observou-se que num primeiro momento a corrosão abre portas para a incrustação, mas quando se encontra muito avançada, esta provavelmente inibe a fixação dos moluscos. A vida útil dos revestimentos e a corrosão dos materiais testados deveriam ser avaliadas em experimento de longa duração com a finalidade de validar a tecnologia testada.

\section{Agradecimentos}

Ao financiamento do projeto pela AES Tietê/ ANEEL.

\section{Referências}

Bergonci, P. E. A.; Mansur, M. C. D.; Pereira, D.; Santos, C. P. 2009. Population sampling of the golden mussel, Limnoperna fortunei (Dunker, 1857), based on artificial ceramic substrate. Biotemas, 22 (3): 85-94.

Boltovskoy, D.; Cataldo, D. H. 1999. Population dynamics of Limnoperna fortunei, an invasive fouling mollusc, in the Lower Paraná River (Argentina). Biofouling, 14: 255-263.

Caprari, J. J. 2006. Pinturas antiincrustantes. In: Darrigran, G. \& Damborenea, C. (Eds). Bio-invasión del mejillón dorado en el continente americano. Edulp, Buenos Aires, Argentina, p.181211.

Caprari, J. J.; Lecot, C. J. 2001. El control de bivalvos invasores Limnoperna fortunei (Dunker, 1857) en la central hidroelectrica Yaciretá mediante pinturas. Anais do Seminario Internacional Gestión Ambiental e Hidroelectricidad, Complejo Hidroeletrico Salto Grande, Yaciretá, Argentina, p.1-13.

Darrigran, G. E.; Mansur, M. C. D. 2006. Distribuição, abundância e dispersão. In: Darrigran, G. A. \& Damborenea, C. (Eds). Bioinvasión del mejillón dorado en el continente americano. Edulp, La Plata, Argentina, p.93-110.

Faria, E. A.; Branco, J. R. T.; Campos, M. C. S.; Oliveira, M. D.; Rolla, M. E. 2006. Estudo das características antiicrustantes de materiais. Revista da Escola de Minas, 59: 233-238.

Filippo, R. 2004. Incidência dos mexilhões dourados nos reservatórios. Linha Direta, 307: 14.

Kuhlmann, M. L.; Hayashida, C. Y. E.; Araújo, R. P. A. 2000. Using Chironomus (Chironomidae: Diptera) mentum deformities in environmental assesment. Acta Limnologica Brasiliensis, 12: 55-61. 
Mansur, M. C. D.; Pereira, D.; Santos, C. P.; Bergonci, P. E. A.; Thormann, B. M. 2009. Colonização de substrato artificial de madeira pelo mexilhão dourado, Limnoperna fortunei (Dunker, 1857) (Bivalvia, Mytiloida, Mytilidae), no Delta do rio Jacuí (RS, Brasil). Biotemas, 22: 75-80.

Marcus, E. B. 1984. 66 Bryozoa. In: Schaden, R. (Org.). Manual de identificação de invertebrados límnicos do Brasil. CNPq, Brasília, Brasil, p.1-24.

Mugnai, R.; Nessimian, J. L.; Baptista, D. F. 2010. Manual de identificação de macroinvertebrados aquáticos do estado do Rio de Janeiro. Technical Books, Rio de Janeiro, 174pp.

Palombo, C. R.; Pereira, M. D. B. 1992. Monitoramento de plantas aquáticas por satélite. Ambiente, 6: 49-54.

Pareschi, D. C.; Matsumura-Tundisi, T.; Medeiros, G. R.; Luzia, A. P.; Tundisi, J. G. 2008. First occurrence of Limnoperna fortunei (Dunker, 1857) in the Rio Tietê watershed (São Paulo State, Brazil). Brazilian Journal Biology, 68 (4): 1107-1114.

Santos, C. P.; Würdig, N. L.; Mansur. M. C. D. 2005. Fases larvais do mexilhão dourado Limnoperna fortunei (Dunker) (Mollusca, Bivalvia, Mytilidae), na bacia do lago Guaíba, Rio Grande do Sul, Brasil. Revista Brasileira de Zoologia, 22 (3): 702-708.

Santos, C. P.; Mansur. M. C. D.; Würdig, N. L. 2008. Variações no comprimento dos indivíduos de uma população de mexilhão dourado, Limnoperna fortunei (Mollusca, Bivalvia, Mytilidae), ao longo do ano, na Praia do Veludo, Lago Guaíba, Rio Grande do Sul, Brasil. Revista Brasileira de Zoologia, 25: 389-396.
Scheer, B. T. 1945. The development of marine faune communities. The Biological Bulletin, 89 (1): 103-121.

Soares, M. F.; Pires, M. J.; Mansur, M. C. D.; Pereira, D.; Santos, C. P. 2008. Desenvolvimento e adequação de tecnologias ambientais para o controle populacional do mexilhão dourado Limnoperna fortunei. CNPq/FEEVALE/PUCRS, Novo Hamburgo, Brasil, 99pp. Disponível em<http://cadastrocthidro.ana.gov.br/arquivos/ relatorio_cnpq.pdf $>$ Acesso em 9 de julho de 2009.

Tundisi, J. G.; Matsumura-Tundisi, T.; Pareschi, D. C.; Luzia, A. P.; Haeling, P. H.; Frollini, E. H. 2008. A bacia hidrográfica do Tietê/Jacaré: Estudo de caso em pesquisa e gerenciamento. Estudos Avançados, 22 (63): 159-172.

Uryu, Y.; Iwasaki, K.; Hinque, M. 1996. Laboratory experiments on behaviour and movement of a freshwater mussel, Limnoperna fortunei (Dunker). Journal of Molluscan Studies, 62: 327-341.

Valentin, J. L. 2000. Ecologia numérica: uma instrodução à análise multivariada de dados ecológicos. Interciência, Rio de Janeiro, Brasil, 117pp.

Zar, J. H. 1999. Biostatistical analysis. $4^{\text {th }}$ ed. Prentice Hall, New Jersey, USA, 663pp. 